STOMACH

\title{
Effect of scheduled second therapeutic endoscopy on peptic ulcer rebleeding: a prospective randomised trial
}

\author{
P W Y Chiu, C Y W Lam, S W Lee, K H Kwong, S H Lam, D T Y Lee, S P Y Kwok
}

Gut 2003;52:1403-1407

See end of article for authors' affiliations

Correspondence to:

Dr P W Y Chiu, Surgery

United Christian Hospital,

130 Hip Woo St, Kwun

Tong, Hong Kong SAR,

China; pchiu@hkstar.com

Accepted for publication 14 May 2003

\begin{abstract}
Aim: Recurrent bleeding after initial haemostasis is an important factor that directly relates to the outcome in the management of peptic ulcer bleeding. Conflicting reports have been published concerning the effectiveness of scheduled second therapeutic endoscopy on ulcer rebleeding. We investigate the use of scheduled second endoscopy with appropriate therapy on peptic ulcer rebleeding.

Methods: From August 1999 to January 2001, we prospectively randomised patients who had endoscopically confirmed bleeding peptic ulcer with stigmata of acute bleeding, visible vessel, or adherent clot into two groups. Endoscopic therapy was standardised to initial epinephrine injection and subsequent heater probe application. The study group $(n=100)$ received scheduled second endoscopy 16-24 hours after initial haemostasis, and further therapy was applied if endoscopic stigmata persisted, as above. The control group $(n=94)$ were observed closely. Those patients that developed rebleeding in either group underwent operation if further endoscopic therapy failed. Outcome measures included ulcer rebleeding, transfusion, duration of stay, and mortality.

Results: After initial endoscopic haemostasis, 194 eligible patients were randomised into two groups. Thirteen patients in the control group developed recurrent bleeding within 30 days while five patients in the study group sustained recurrent bleeding $(p=0.0314)$ (relative risks $0.33,95 \%$ confidence interval $0.1-$ 0.96). The number of patients that required surgery for recurrent bleeding was six in the control group and one in the study group $(p=0.05)$. There was no difference in duration of hospital stay, transfusion, or mortality between the two groups.

Conclusions: A scheduled repeat endoscopy with appropriate therapy 16-24 hours after initial endoscopic haemostasis reduces the number of cases of recurrent bleeding.
\end{abstract}

$\mathrm{T}$ he aim of a scheduled second endoscopy is to detect and retreat ulcers that are at risk of recurrent bleeding. By doing so, we hope that we can reduce the number of episodes of recurrent bleeding and hence decrease the number of operations necessary to treat recurrent bleeding, and lower mortality. ${ }^{1}$

The concept of a scheduled second endoscopy is not new. In one of the earliest trials on endoscopic therapy for ulcer bleeding, Chung et al employed an approach of a routine repeat endoscopy within 24 hours after initial endoscopic haemostasis. ${ }^{2}$ On the second endoscopy, he found that six of 32 ulcers were still having persistent stigmata of haemorrhage, and retreatment achieved haemostasis in all. Although this earliest study gave encouraging results, subsequent prospective randomised controlled trials reported conflicting results on the use of scheduled second endoscopy. ${ }^{3-6}$ Some of the trials consisted of a small sample size, and the definition of recurrent bleeding varied between the different studies. The endoscopic techniques were also different in these studies. Because of the conflicting results in the literature, we conducted a prospective, randomised, controlled trial to study the effect of scheduled second endoscopy with appropriate therapy on recurrent bleeding in peptic ulcer.

\section{METHODS}

Participants

This was a single centre, prospective, randomised, controlled trial, which was approved by the ethics committee of the United Christian Hospital, Hong Kong. United Christian Hospital is a large regional hospital located over the east of Kowloon, which serves a population of 800 000. All patients who present to our unit with bleeding peptic ulcers receive primary endoscopy within 24 hours after admission. From
August 1999 to January 2001, we included patients aged 1590 years that underwent successful endoscopic haemostasis for bleeding peptic ulcers within 24 hours after admission. Patients were excluded from randomisation if the bleeding was not controlled at primary endoscopy, those without informed consent, those that bled from carcinoma of the stomach or other non-ulcer lesions such as Dieulafoy lesions, and those patients that were ASA grade 5 .

\section{Randomisation and concealment}

Patients were randomised by sequentially numbered sealed opaque envelops after primary endoscopy by two investigators (PWYC and CYWL) who were not involved in the clinical management. The study group received a scheduled second endoscopy with appropriate therapy within 16-24 hours after initial endoscopy, while the control group were observed closely.

\section{Classification of bleeding peptic ulcers}

We used the Forrest classification for endoscopic grading of bleeding peptic ulcers. ${ }^{7}$ With a view to reducing interobserver bias on the grading of endoscopic stigmata, we recorded the complete process of endoscopic therapy for the initial 30 patients and video records were reviewed to audit endoscopic grading. Afterwards, all endoscopic views of the ulcers were photographed before and after therapy for comparison. During primary endoscopy, the bleeding ulcers with endoscopic stigmata of acute bleeding, visible vessel, or adherent clot were included in our study.

\section{Endoscopist and endoscopic techniques}

We limited the endoscopist to six surgeons. The endoscope employed was either an Olympus GIF-XQ230 or a 240 
fibrescope (Olympus Co. Ltd, Hong Kong). Endoscopic therapy was standardised to initial injection of 1:10 000 adrenaline around the ulcer to achieve a tamponade effect, followed by simultaneous application of a $2.3 \mathrm{~mm}$ heater probe (CD-120U) at $20 \mathrm{~J}$ per goal consecutively until achievement of a coaptive effect. The same method was used on scheduled second endoscopy if endoscopic stigmata persisted as acute spurting, oozing, visible vessel, or adherent clot. The adherent clot was vigorously washed away with either a "waterpik" or waterjet from the heater probe. The success of endoscopic haemostasis was defined as cessation of bleeding together with achievement of cavitation over the ulcer after application of the heater probe.

Both groups of patients received intravenous omeprazole $40 \mathrm{mg}$ every 12 hours after the initial endoscopy for three consecutive days. They were monitored closely and underwent clinical reviews, with blood pressure, pulse, respiratory rate, and urine output measured hourly for the first 24 hours, followed by close observation for symptoms and signs of recurrent bleeding throughout the stay in hospital.

\section{Outcome definitions}

The primary outcome parameter was recurrent bleeding, which was stratified into recurrent bleeding within the first 24 hours, within the first week, and within the first 30 days. Recurrent bleeding from the peptic ulcer is defined by clinical parameters including: (1) fresh haematemesis or fresh blood passing from the nasogastric tube; (2) passage of fresh melena with a systolic blood pressure of less than $100 \mathrm{~mm} \mathrm{Hg}$ or pulse rate greater than 100 beats per minute; (3) a drop in haemoglobin level of more than $4 \mathrm{~g} / \mathrm{dl}$ within 24 hours; or (4) requirement for continuous blood transfusion of more than 4 units within 24 hours to maintain blood pressure or haemoglobin level. We performed emergency endoscopy to confirm clinical recurrent bleeding, which was defined as persistent endoscopic stigmata of acute spurting or oozing, visible vessel, or adherent clots, with appearance of blood clots, or coffee ground materials in the stomach or duodenum. Secondary outcome measures included the number of operations performed, amount of transfusion given, duration of hospital stay, and mortality rate. Surgery was performed in those patients in whom bleeding could not be stopped by a scheduled second endoscopic therapy, those that developed clinical recurrent bleeding, and failed emergency endoscopic therapy. Surgical interventions included plication of ulcer, vagotomy and drainage, and gastrectomy. The choice of surgery for those patients was considered individually. We defined the threshold for transfusion as: (1) those patients that had a systolic blood pressure of less that $100 \mathrm{~mm} \mathrm{Hg}$ or those with a pulse rate greater than 100 per minute; and (2) those that were haemodynamically stable but with a haemoglobin level of $8 \mathrm{~g} / \mathrm{dl}$ or less.

\section{Statistics}

Sample size estimation was based on previous experience of management of peptic ulcer bleeding from this institute, together with the reference rate of recurrent bleeding from other studies. We assumed that the rate of recurrent bleeding in the control group would be $20 \%$, and we planned to detect a $15 \%$ difference in favour of a scheduled second endoscopy. We defined alpha as 0.05 and beta as 0.2 , and a sample size of at least 79 patients was required for each treatment arm. ${ }^{8}$ Patient characteristics and outcome measures were compared using the Student's $t$ test for parametric data and the MannWhitney $U$ test for non-parametric data. For analysing data in proportions, we used the $\chi^{2}$ test or Fisher's exact test if one of the expected values was less than 5 . We calculated the relative risks with $95 \%$ confidence interval (CI) for recurrent bleeding, number of operations, morbidities, and mortalities.
We used the Kaplan-Meier curve to represent the probability of recurrent bleeding within 30 days after initial haemorrhage, and compared the two groups using the log rank test. ${ }^{9}$ A p value of less than 0.05 was considered to be statistically significant. Statistical analysis was performed with SPSS software (version 7.5, SPSS Inc.; Chicago, Illinois, USA). Analysis was performed according to intention to treat principles. $^{10}$

\section{RESULTS \\ Characteristics of patients}

From August 1999 to January 2001, a total of 287 patients were admitted to our unit with bleeding peptic ulcers. All received primary therapeutic endoscopy within 24 hours after admission. A total of 206 were found to have bleeding gastric or duodenal ulcers with endoscopic stigmata of acute spurting, oozing, visible vessel, or adherent clot. Primary therapeutic endoscopy failed to achieve haemostasis in 10 and they were subjected to immediate surgery. Two patients were excluded after inclusion because biopsy of the ulcer confirmed carcinoma of the stomach. A total of 194 patients were included in our trial after informed consent was obtained. They were randomised into two groups. Baseline characteristics of the patients in both groups are shown in table 1 . The groups were comparable in age, sex distribution, percentage of coexisting illnesses, and distribution of ASA class. With respect to the characteristics of the ulcer, there were no differences between the study group and control group in terms of location, size, and initial endoscopic stigmata of recent haemorrhage. Mean size of the ulcers was $1.0(0.5) \mathrm{cm}$ for the study group and $0.9(0.5) \mathrm{cm}$ for the control group (table 1).

\section{Outcome of patients}

After the first 24 hours of the initial endoscopy, one patient in the study group developed recurrent bleeding while none of the patients in the control group showed signs of recurrent bleeding. Within the first seven days after initial bleeding, 13 patients $(13.8 \%)$ in the control group developed recurrent bleeding while four patients $(4 \%)$ in the study group developed recurrent bleeding $(\mathrm{p}=0.027$, Fisher's exact test; relative risk 0.29 (95\% CI 0.09-0.92)). Within 30 days after the initial endoscopy, 13 patients $(13.8 \%)$ in the control group developed recurrent bleeding while five patients $(5.0 \%)$ in the study group developed clinical recurrent bleeding from ulcers $\left(\mathrm{p}=0.034, \chi^{2}\right.$ test; relative risk 0.33 (95\% CI $0.11-$ $0.96))$.

When we analysed the probability of recurrent bleeding within 30 days after initial bleeding using the Kaplan-Meier curve and compared the results of the two groups, we found that by performing a scheduled second endoscopy with appropriate therapy we could reduce the probability of recurrent bleeding in the study group $(p=0.031$, log rank test) (fig 1).

In the study group, four of the five cases of recurrent bleeding were controlled by another endoscopic therapy. One patient $(1 \%)$ required surgery to achieve haemostasis after recurrent bleeding. In the control group, recurrent bleeding could not be stopped endoscopically in six of 13 patients, and surgery was required $(6.4 \%)$. Polya gastrectomies were performed in all patients that required surgery for control of ulcer bleeding. There was a trend towards fewer numbers of operations performed to salvage recurrent bleeding in the study group $(\mathrm{p}=0.05$, Fisher exact test; relative risk 0.15 $(95 \%$ CI $0.02-1.26))$. A summary of the outcome of patients is shown in fig 2.

The mean number of units of blood transfused in the study group was 1.9 (1.7) while that transfused for the control group was 2.1 (2.3). There was no difference between the two 


\begin{tabular}{|c|c|c|c|}
\hline & $\begin{array}{l}\text { Control group (no } \\
\text { second OGD) }\end{array}$ & $\begin{array}{l}\text { Study group } \\
\text { (second OGD) }\end{array}$ & p Value \\
\hline $\mathrm{n}$ & 94 & 100 & \\
\hline Mean age* & $67.5(12.6)$ & $68.7(13.9)$ & 0.53 \\
\hline $\operatorname{Sex}(M / F)$ & $62 / 32$ & $70 / 30$ & 0.51 \\
\hline Coexisting illnesses (\%) & $69.1 \%$ & $65 \%$ & 0.54 \\
\hline \multicolumn{4}{|l|}{ ASA (n) } \\
\hline I & 43 & 44 & 0.23 \\
\hline ॥I & 37 & 30 & \\
\hline III & 15 & 23 & \\
\hline IV & 1 & 3 & \\
\hline History of peptic ulcer (n) & 21 & 21 & 0.86 \\
\hline Haemoglobin $(\mathrm{g} / \mathrm{dll})^{*}$ & $9.4(2.7)$ & $8.9(2.6)$ & 0.33 \\
\hline Shock on admission (n (\%)) & $44(46.8 \%)$ & $48(48 \%)$ & 0.87 \\
\hline Haematemesis (n) & 13 & 13 & 0.87 \\
\hline \multicolumn{4}{|l|}{ Ulcer location (n) } \\
\hline Stomach & 40 & 44 & 0.84 \\
\hline Duodenum & 54 & 56 & 0.95 \\
\hline Ulcer size $(\mathrm{cm})^{*}$ & $0.9(0.5)$ & $1.0(0.5)$ & 0.088 \\
\hline \multicolumn{4}{|l|}{ Endoscopic stigmata on 1st OGD (n) } \\
\hline Active spurting & 14 & 10 & 0.55 \\
\hline Active oozing & 32 & 33 & \\
\hline Visible vessel & 27 & 37 & \\
\hline Adherent clot & 21 & 20 & \\
\hline Helicobacter pylori infection (n) & 44 & 56 & 0.47 \\
\hline Use of aspirin (n) & 6 & 12 & 0.18 \\
\hline \multicolumn{4}{|l|}{ Initial endoscopic therapy } \\
\hline Injection of adrenaline $(\mathrm{ml})^{*}$ & $9.1(4.4)$ & $8.8(3.8)$ & 0.54 \\
\hline \multicolumn{4}{|l|}{ Heater probe pulses } \\
\hline Median & 4 & 4 & \\
\hline Range & $0-15$ & $0-10$ & 0.88 \\
\hline \multicolumn{4}{|l|}{ Scheduled 2nd endoscopy } \\
\hline No of patients required 2nd therapy (n (\%)) & - & $35(35 \%)$ & - \\
\hline
\end{tabular}

groups in units of blood transfused (Student's $t$ test, $\mathrm{p}=0.44)$.

Median duration of hospital stay for both groups of patients was four days, and the need for intensive care was also similar between the two groups. We found no significant difference in the number of morbidities between the two groups. Moreover, there was no difference in mortality between the two groups (table 2). There were three morbidities in the study group and six in the control group. Six patients had complications of the cardiovascular system, including angina, myocardial infarction, and cardiac failure. Two patients had wound infections after gastrectomies and one patient sustained a cerebral vascular accident. Five of

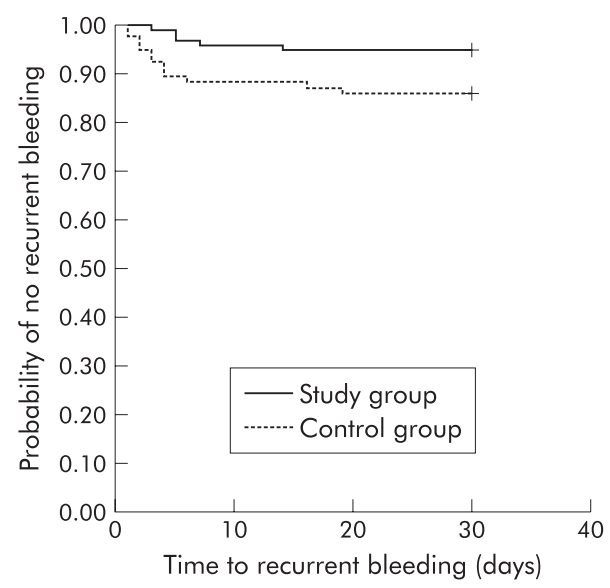

Figure 1 Kaplan-Meier estimation on the probability of recurrent bleeding within 30 days after therapeutic endoscopy in the control and study groups. nine patients who had complications were suffers of recurrent bleeding.

\section{Outcome on endoscopic treatment}

Of 100 patients who received a scheduled second endoscopy, 35 (35\%) underwent retreatment (table 3 ). There was no difference in the volume of adrenaline injected in the initial endoscopy between the two groups (control group 8.8 (3.9) ml, study group 9.1 (4.4) $\mathrm{ml}$; Student's $t$ test, $\mathrm{p}=0.67)$. The mean volume of adrenaline injected on the second endoscopy was $6.9(3.0) \mathrm{ml}$. The mean total volume of adrenaline injected was 9.1 (4.4) $\mathrm{ml}$ in the control group and 11.1 (5.7) $\mathrm{ml}$ in the study group (Student's $t$ test, $\mathrm{p}=0.008$ ). There was a significant difference in the total volume of adrenaline injected between the two groups.

Mean total energy applied during the treatment with heater probe in the study group was 110.2 (52.0) J while it was 95.3 (44.2) $\mathrm{J}$ for the control group. There was also a significant difference (Student's $t$ test, $\mathrm{p}=0.047$ ) in the total amount of energy applied between the two groups.

\section{DISCUSSION}

\section{Impact of recurrent bleeding}

Before the era of endoscopic therapy, medical therapy with appropriate surgical interventions accounted for $20 \%$ of mortalities. ${ }^{11}$ After the introduction of primary endoscopic therapy, mortality from bleeding peptic ulcers was reduced to approximately $5-14 \% .{ }^{12-14}$ It can achieve primary haemostasis in up to $90 \%$ of cases. ${ }^{14}{ }^{15}$ However, there is a significant risk of recurrent bleeding, ranging from 5\% to 30\%, which varies between institutes. Recurrent bleeding is one of the most important risk factors for mortality. ${ }^{16}$ Most recurrent bleeding occurs within the first week after the primary therapeutic endoscopy. While therapeutic endoscopy at the 


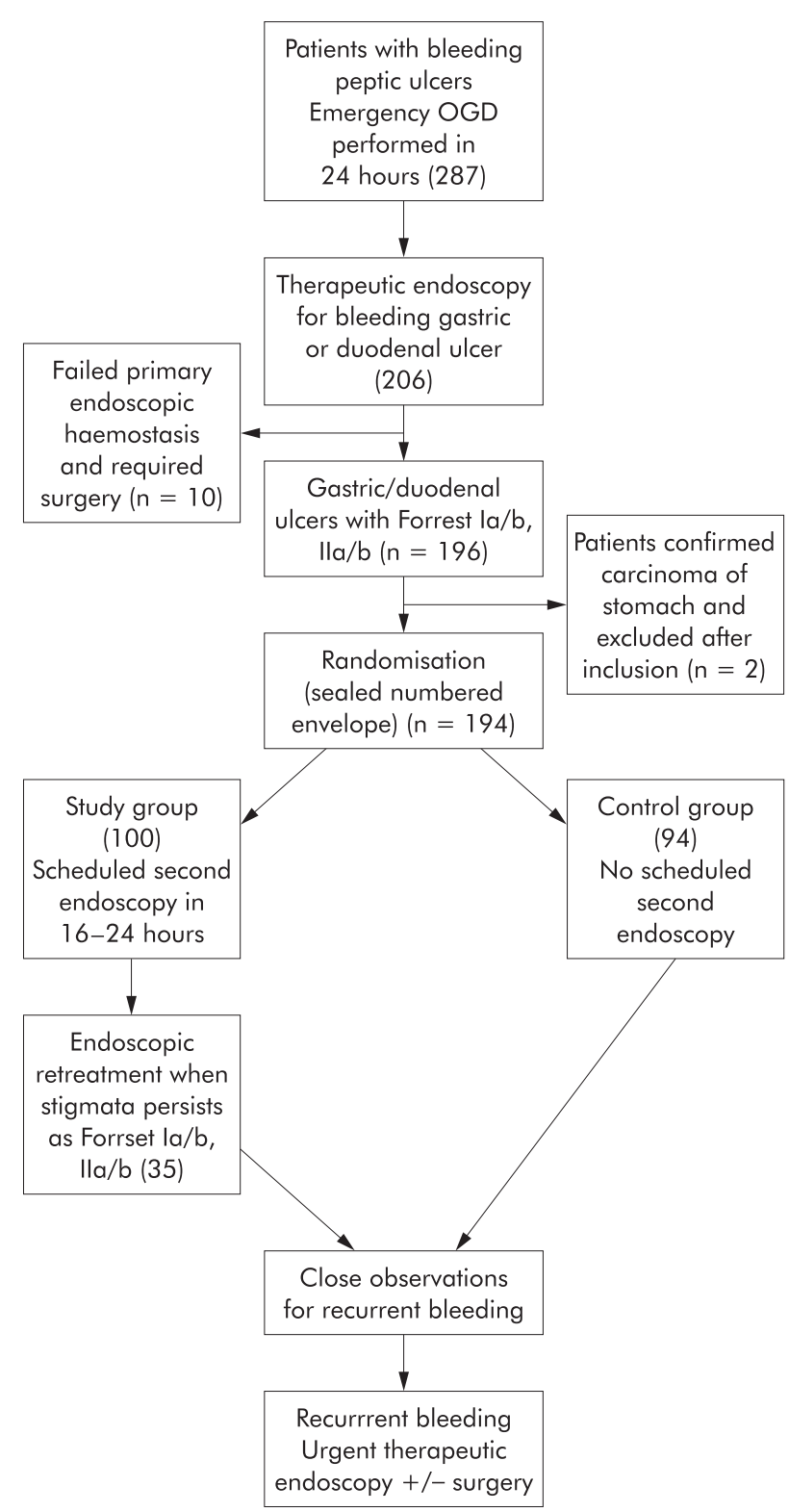

Figure 2 Partipant flow chart. OGD, oesophagogastroduodenoscopy.
Table 3 Outcome on second endoscopy in the control and study groups

\begin{tabular}{|c|c|c|c|}
\hline & $\begin{array}{l}\text { Control group } \\
(n=94)\end{array}$ & $\begin{array}{l}\text { Study group } \\
(n=100)\end{array}$ & p Value \\
\hline \multicolumn{4}{|c|}{ Mean volume of adrenaline injected $(\mathrm{ml}) \dagger$} \\
\hline In first OGD & $8.8(3.9)$ & $9.1(4.4)$ & 0.67 \\
\hline In second OGD & - & 6.9 (3.0) & - \\
\hline Total & $9.1(4.4)$ & $11.1(5.7)$ & $0.008^{*}$ \\
\hline $\begin{array}{l}\text { Mean total heat probe } \\
\text { energy applied (J)† }\end{array}$ & $95.3(44.2)$ & 110.2 (52.0) & $0.047^{*}$ \\
\hline
\end{tabular}

time of recurrent bleeding can stop bleeding in half of cases, surgical haemostasis is contemplated in the remainder ${ }^{18}$

\section{Scheduled second endoscopy}

Perhaps there is a time before recurrent bleeding where we can detect persistence of the stigmata of haemorrhage and provide a second treatment to prevent further bleeding (that is, provide treatment before the rebleed). Several randomised trials have attempted to address this issue. One paper, published in 1994, found a trend towards better outcome with second endoscopy, ${ }^{3}$ but the difference was not statistically significant. Another multicentre trial from Germany, using combined endoscopic injection of adrenaline and fibrin glue, found no difference in the rate of recurrent bleeding between the group with a programmed second endoscopy and the group without. ${ }^{6}$ However, this trial involved five centres which recruited 105 cases over a period of two years. There were doubts concerning the experience in treating bleeding peptic ulcer from each individual centre as only 10 cases were included from each centre per year. Saeed et al conducted a randomised trial from a different angle. ${ }^{5}$ They performed scheduled second therapeutic endoscopy on patients who were categorised as having a high risk of recurrent bleeding based on Baylor's score. They found that the group that received a second therapeutic endoscopy was associated with a significantly lower recurrent bleeding. Numerous prospective randomised trials reported conflicting results regarding the use of scheduled second endoscopy on prevention of recurrent bleeding. There are several explanations for this. Previous randomised trials probably recruited a suboptimal number of samples. Moreover, the endoscopic techniques of haemostasis have been evolving over the past decade. In the early 1990s, single therapy was the optimal mode of endoscopic haemostasis. Near the end of the 1990s, evidence emerged that combination therapy with injection and thermal therapy until achievement of cavitation may be

Table 2 Outcome in the control and study groups

\begin{tabular}{|c|c|c|c|c|}
\hline Outcome & $\begin{array}{l}\text { Control group } \\
(\mathrm{n}=94)\end{array}$ & $\begin{array}{l}\text { Study group } \\
(n=100)\end{array}$ & Relative risk $(95 \% \mathrm{Cl})$ & p Value \\
\hline \multicolumn{5}{|l|}{ Recurrent bleeding } \\
\hline Day 1 & 1 & 0 & - & 0.485 \\
\hline Day 7 & 13 & 4 & $0.29(0.09-0.92)$ & $0.027^{*}$ \\
\hline Day 30 & 13 & 5 & $0.33(0.11-0.96)$ & $0.034^{*}$ \\
\hline $\begin{array}{l}\text { Successful endoscopic retreatment } \\
\text { after recurrent bleeding }\end{array}$ & 7 & 4 & $0.29(0.03-3.37)$ & 0.596 \\
\hline $\begin{array}{l}\text { Surgery } \\
\text { Hospital stay (days) }\end{array}$ & \multicolumn{2}{|c|}{ Hospital stay (days) } & $0.15(0.02-1.26)$ & 0.050 \\
\hline Median & 4 & 4 & - & - \\
\hline Range & $2-24$ & $2-24$ & - & 0.109 \\
\hline Units of blood transfused $†$ & $2.1(2.3)$ & $1.9(1.7)$ & - & 0.44 \\
\hline Death within 30 days (\%) & $2(2.1 \%)$ & $2(2 \%)$ & $0.939(0.13-6.80)$ & 1.0 \\
\hline Morbidities & 6 & 3 & $0.45(0.11-1.87)$ & 0.32 \\
\hline
\end{tabular}

tMean (SD).

*Significant difference. 
advantageous. ${ }^{19} 20$ The outcome definitions from the various trials were also different. In some studies, recurrent bleeding was defined using clinical or endoscopic evidence, and persistence of endoscopic stigmata on second endoscopy were also considered as recurrent bleeding. The heterogeneity of endoscopic therapy and the variation in outcome definitions led to conflicting results from these different trials.

In our study, we defined recurrent bleeding using clinical parameters, and confirmed this with endoscopy. We included ulcers with endoscopic stigmata of active bleeding, visible vessel, or adherent clot. Half of our patients presented initially with shock, and two thirds had coexisting illnesses. We believe that our sample represented a group of patients that carried a significant risk of recurrent bleeding. ${ }^{13}{ }^{21}$ We standardised our endoscopic technique to initial injection of adrenaline, followed by thermocoagulation with a heater probe. ${ }^{16}$ We used a sample of appropriate size statistically. ${ }^{8}$ Our study showed that scheduled second endoscopy with appropriate therapy reduced the number of cases of recurrent haemorrhage significantly $(\mathrm{p}=0.034$; relative risk $0.33(95 \%$ CI $0.11-0.96)$ ). We also demonstrated a reduction in the number of operations performed for ulcer rebleeding.

Thirty five per cent of patients required a second therapy. We believe that we achieved a reasonable amount of retreatment from the second endoscopy. The yield of scheduled second endoscopy depends on the performance of the primary endoscopy, level of risk of the population treated, and the endoscopic technique. If the percentage of retreatment is high, there may be room for improvement in the primary endoscopy. If the percentage of retreatment is low, scheduled second endoscopy may not be cost effective. Lau et al addressed the issue of performing a second endoscopy when an ulcer rebleeds which may perhaps be an option if the percentage of retreatment on second endoscopy is low. ${ }^{18}$ In our current study, the amount of total adrenaline injected and heat probe energy delivered was significantly higher in the study group than in the control group. We believe that by delivering a high dose of endoscopic therapy in a sequential strategy, we can achieve a significantly lower recurrent bleeding rate.

Only one patient in the study group required surgical intervention for recurrent bleeding, while six operations were performed in the control group. There was a trend towards a reduction in the number of operations although this was not statistically significant. We still consider this to be an important issue as even a small reduction in the number of operations represents a great improvement in the outcome of patients.

\section{Possible complications}

Despite the previous concern of reapplication of a heat probe in patients who have undergone heat probe treatment, our study showed that reapplication of heat probe 16-24 hours after the initial endoscopy did not result in a large amount of iatrogenic perforation, as reported previously. ${ }^{12}{ }^{18}$ One of the explanations for this is that in a clean field with clear endoscopic view on scheduled second endoscopy, the endoscopist can achieve better targeting of the heat probe than in a field of active recurrent bleeding.

\section{CONCLUSIONS}

From the results of our current randomised study, we can conclude that a scheduled second endoscopy with appropriate therapy reduced the amount of recurrent bleeding from bleeding peptic ulcers. There was also a trend towards a reduction in the number of operations performed for recurrent bleeding.

\section{ACKNOWLEDGEMENTS}

P Chiu and C Lam were the principle investigators. SW Lee and D Lee were responsible for the statistical methods and analysis. KH Kwong, SH Lam, and S Kwok were supervisors on the project.

\section{Authors' affiliations}

P W Y Chiv, C Y W Lam, S W Lee, K H Kwong, S H Lam, D T Y Lee,

S P Y Kwok, Department of Surgery and Endoscopy Centre, United

Christian Hospital, Kwun Tong, Hong Kong SAR, China

\section{REFERENCES}

1 Saeed ZA. Second thoughts about second-look endoscopy for ulcer bleeding? Endoscopy 1998:30:650-2.

2 Chung SCS, Leung JWC, Steele RJC, et al. Endoscopic injection of adrenaline for actively bleeding ulcers: a randomized trial. BMJ 1988;296:1631-3.

3 Villanueva C, Balanzo J, Torras X, et al. Value of a second look endoscopy after injection therapy for bleeding peptic ulcer: a prospective and randomized trial. Gastrointest Endos 1994:40:34-9.

4 Lin CK, Lai KH, Lo GH, et al. The value of second-look endoscopy after endoscopic injection therapy for bleeding peptic ulcer. Gastroenterology 1996; 110:A177.

5 Saeed ZA, Cole RA, Ramirez FC, et al. Endoscopic retreatment after successful initial haemostasis prevents ulcer rebleeding: a prospective randomized trial. Endoscopy 1996;28:288-94.

6 Messmann H, Schaller P, Andus T, et al. Effect of programmed endoscopic follow-up examinations on the rebleeding rate of gastric or duodenal peptic ulcers treated by injection therapy: a prospective randomized controlled trial. Endoscopy 1998;30:583-9.

7 Lau JYW, Chung SCS, Leung JW, et al. Evolutions of stigmata of hemorrhage in bleeding peptic ulcers: a sequential endoscopic study. Endoscopy 1998:30:513-18.

8 Dawson B, Trapp RG. Basic and clinical biostatistics, 3rd ed. New York: McGraw Hill, 2001

9 Kaplan EL, Meier P. Nonparametric estimation from incomplete observations. J Am Stat Assoc 1958;53:457-81.

10 Moher D, Schulz KF, Altman DG. The CONSORT statement: revised recommendations for improving the quality of reports of parallel-group randomized trials. Lancet 2001;357:1191-4.

11 Ohmann C, Imhof M, Roher HD. Trends in peptic ulcer bleeding and surgical treatment. World J Surg 2000;24:284-93.

12 Rollhauser C, Fleischer DE. Nonvariceal upper gastrointestinal bleeding: an update. Endoscopy 1997;29:91-105.

13 Rockall TA, Logan RFA, Devlin HB, et al. Incidence of and mortality from acute upper gastrointestinal hemorrhage in the United Kingdom. BMJ 1995:311:222-6.

14 Sacks HS, Chalmers TC, Blum AL, et al. Endoscopic hemostasis: An effective therapy for bleeding peptic ulcers. JAMA 1990;264:494-9.

15 Cook DJ, Guyatt GH, Salena BJ, et al. Endoscopic therapy for acute nonvariceal upper gastrointestinal hemorrhage: a meta-analysis. Gastroenterology 1992:102:139-48.

16 Rollhauser C, Fleischer DE. Current status of endoscopic therapy for ulcer bleeding. Baillieres Clin Gastroenterol 2000;14:391-410.

17 Chung SCS. Preventing ulcer rebleeding: the role of second look endoscopy. Can J Gastroenterol 1999;13:409-11.

18 Lau JYW, Sung JJY, Lam YH, et al. Endoscopic retreatment compared with surgery in patients with recurrent bleeding after initial endoscopic control of bleeding ulcers. N Engl J Med 1999;340:751-6.

19 Chung SCS, Lau JYW, Sung JJY, et al. A randomized comparison between adrenaline injection alone and adrenaline plus heat probe treatment for actively bleeding ulcers. BMJ 1997:314:1307-11.

20 Lin HJ, Tseng GY, Perng CL, et al. Comparison of adrenaline injection and bipolar electrocoagulation for the arrest of peptic ulcer bleeding. Gut 1999:45:715-19.

21 Laine L, Peterson WL. Bleeding peptic ulcer. N Engl J Med 1994;331:717-27. 